in adults where the primary illness predisposes to infection. This is also indicated in patients in whom the spleen has been removed whenever the patient is receiving corticosteroids.

\section{Summary}

During 19611,167 patients had splenectomy performed in England and Wales.

A postal follow-up of these patients was carried out, information being sought from the family doctor or hospital consultant in whose care the patient had been. Altogether, details were achieved from $1,118(96 \%)$.

The reason for splenectomy, cause of death, and occurrence of infection in the subsequent two to three years is reported.

It was confirmed that pneumococcal septicaemia and other fulminating infections sometimes follow splenectomy. Such infectiors are more common in childhood, in patients where the underlying disease predisposes to infection, and in patients on continued treatment with corticosteroids.

Further study is needed before an authoritative estimate of the risk in relation to age and underlying condition can be achieved. In the meanwhile it is suggested that splenectomy be avoided whenever possible during the first four years of life, and that post-operative antibiotic cover for two years might well be provided in young children, in patients where the primary illness may predispose to infection, and in any patient while receiving corticosteroid therapy.
This study has been made possible by the co-operation of hundreds of doctors throughout the country. We acknowledge with thanks the trouble that family doctors have taken to supply data about their patients, and to hospital staff for abstracting relevant data from hospital records.

This could not have been carried out without the good will of senior administrative medical officers in all regions and the generosity of the many surgeons and physicians who have allowed access to their records. When patients had "disappeared" the surgeon has often gone to considerable effort to trace them and provide the information requested.

Executive council staffs have played a large part in tracing patients who had changed their doctor.

All the vecretarial work has been done by Mrs. M. Malaghan.

\section{REFERENCES}

Carpenter, A. F., Wintrobe, M. M., Fuller, E. A., Haut, A., and Cartwright, G. E. (1959). f. Amer. med. Ass., 171, 1911.

Doan, C. A., Bouroncle, B. A., and Wiseman, B. K. (1960). Ann. intern. Med., 53, 861

Edwards, H. C. (1951). Lancet, 2, 601.

Gofstein, R., and Gellis, S. S. (1956). Amer. 7. Dis. Child., 91, 566.

Gordon, R. R. (1960). Arch. Dis. Childh., 35, 259.

Horan, M., and Colebatch, J. H. (1962). Ibid., 37, 398

Huntley, C. C. (1958). Amer. F. Dis. Child., 95, 477.

King, H., and Shumacker, H. B., jun. (1952). Ann. Surg., 136, 239.

Lowdon, A. G. R., Walker, J. H., and Walker, W. (1962). Lancet, 1, 499.

MacPherson, A. I. S. (1959). 7. roy. Coll. Surg. Edinb., 4, 305.

Robinson, T. W., and Sturgeon, P. (1960). Pediatrics, 25, 941.

Smith, C. H., Erlandson, M., Schulman, I., and Stern, G. (1957). Amer. 7. Med., 22, 390 .

\title{
Calcium Phosphate and Oxalate Ion-products in Normal and Stone-forming Urines
}

\author{
B. E. C. NORDIN,* M.D., PH.D., M.R.C.P. ; W. G. ROBERTSON,* B.SC.
}

Brit. med. F., 1966, 1, 450-453

The common assumption that urine is supersaturated with respect to calcium phosphate and calcium oxalate has not until recently been tested by actual determination of the relevant ionproducts, mainly because of the difficulty of measuring ionic calcium in urine. Several workers have attempted to overcome this problem (Vermeulen et al., 1956; Thomas and Howard, 1959; Nordin, 1959 ; Nordin and Tribedi, 1962), but while their results are of interest none of the methods can be described as satisfactory. The introduction of the dye tetramethylmurexide by Raaflaub (1962) made accurate measurement of urinary ionic calcium practicable for the first time, and, using this technique, he has recently reported calcium phosphate and calcium oxalate ion-products in eight normal urines which he found to be more or less at the saturation level for these salts (Raaflaub, 1963). We have now applied a slightly modified version of Raaflaub's method to the measurement of calcium phosphate and oxalate ion-products in 50 male cases of renalstone disease and 50 male age-matched controls, and the results are presented in this paper.

\section{Methods}

Twenty-four-hour samples of urine were collected with preservative from 50 men attending a renal-stone clinic. Twentythree of them had a calculus at the time of observation, 14 had passed one in the previous year, and 13 had had no stones for more than one year. The 50 controls were age-matched male patients and members of staff who had never suffered from calculi or any other kidney disease.

When the fresh urines were received the $\mathrm{pH}$ and volume were measured and the following analyses performed: total calcium by the modified AutoAnalyzer technique described by MacFadyen et al. (1965) ; oxalic acid by the method of Zarembski and Hodgkinson (1965a, 1965b) ; and ionic calcium by a slight modification of Raaflaub's (1962) method. The latter modification consisted essentially in reading the absorbance of the calcium tetramethylmurexide complex at two wavelengths (480 and 530 millimicrons) as recommended by Ettori and Scoggan (1962) for plasma, instead of at one wavelength only. The reproducibility of the estimation in 20 duplicate determinations was $+6.1 \%$. Phosphate was estimated by the standard AutoAnalyzer method.

\section{Calculations}

The calcium phosphate salt thought to govern the solubility of kidney stones is octocalcium phosphate (MacGregor et al., $1965 \mathrm{a}, 1965 \mathrm{~b})$, and the approximate product $\left[\mathrm{Ca}^{++}\right]^{4}\left[\mathrm{H}^{+}\right]$ $[\mathrm{PO} \overline{\overline{4}}]^{3}$ may be calculated with the help of Table I as follows.

* Medical Research Council, Mineral Metabolism Research Unit, Leeds General Infirmary. 
The negative logarithm of the ionic calcium concentration in (moles per litre $)^{4}$ is derived from the concentration in $\mathrm{mg}$. per $100 \mathrm{ml}$. Similarly, the negative logarithm of the phosphorus concentration in (moles per litre) ${ }^{3}$ is derived from the concentration in $\mathrm{mg}$. per $100 \mathrm{ml}$. To the sum of them is added a $p \mathrm{H}$ correction factor $(\log \alpha)$ to allow for the dissociation of phosphoric acid, obtained from Table I, the final number being the negative logarithm of the product $\left[\mathrm{Ca}^{++}\right]^{4}\left[\mathrm{H}^{+}\right]$ $[\mathrm{PO} \equiv]^{3}$.

The calcium oxalate product $\left[\mathrm{Ca}^{++}\right][\mathrm{Ox}]$ is derived in the same way from Table II by adding together the negative logarithms corresponding to the ionic calcium and oxalate concentrations in mg. per $100 \mathrm{ml}$. The $\mathrm{pH}$ correction is too small to be significant.

The solubility product of octocalcium phosphate is taken as $10^{-43}$ (calculated from Moreno and Brown (1960)) and the

TABLE I.-Calculation of Urinary Octocalcium Phosphate Ion-products. Conversion Table for the Calculation of Octocalcium Phosphate Ionproducts From Urinary $\mathrm{pH}$ and the Concentrations of Ionic Calcium and Total Phosphorus in mg./100 ml.

\begin{tabular}{|c|c|c|c|c|}
\hline $\begin{array}{l}{\left[\mathrm{Ca}^{++}\right] \text {or }[\mathrm{P}]} \\
(\mathrm{mg} . / 100 \mathrm{ml} .)\end{array}$ & $\frac{-4 \log }{\left[\mathrm{Ca}^{++}\right]}$ & $\begin{array}{c}-3 \log \\
{[\mathrm{P}]}\end{array}$ & $\begin{array}{l}{[\mathrm{P}]} \\
\mathrm{mg} . / 100 \mathrm{ml} .\end{array}$ & $\begin{array}{c}-3 \log \\
{[\mathrm{P}]}\end{array}$ \\
\hline $\begin{array}{r}1 \\
2 \\
3 \\
4 \\
5 \\
6 \\
7 \\
8 \\
9 \\
10 \\
11 \\
12 \\
13 \\
14 \\
15 \\
16 \\
17 \\
18 \\
19 \\
20 \\
21 \\
22 \\
23 \\
24 \\
25 \\
26 \\
27 \\
28 \\
29 \\
30\end{array}$ & $\begin{array}{l}14 \cdot 40 \\
13 \cdot 20 \\
12.52 \\
12.00 \\
11 \cdot 60 \\
11.28 \\
11 \cdot 04 \\
10 \cdot 80 \\
10 \cdot 60 \\
10 \cdot 40 \\
10 \cdot 24 \\
10 \cdot 12 \\
9 \cdot 96 \\
9 \cdot 84 \\
9 \cdot 72 \\
9 \cdot 60 \\
9 \cdot 48 \\
9 \cdot 40 \\
9 \cdot 28 \\
9 \cdot 20 \\
9 \cdot 12 \\
9 \cdot 04 \\
8 \cdot 96 \\
8 \cdot 88 \\
8 \cdot 80 \\
8 \cdot 72 \\
8 \cdot 68 \\
8 \cdot 60 \\
8.56 \\
8 \cdot 48\end{array}$ & $\begin{array}{l}10 \cdot 47 \\
9.57 \\
9 \cdot 03 \\
8.67 \\
8.37 \\
8.13 \\
7.95 \\
7.77 \\
7.62 \\
7.47 \\
7.32 \\
7.23 \\
7.14 \\
7.02 \\
6.93 \\
6.87 \\
6.78 \\
6.69 \\
6 \cdot 63 \\
6.57 \\
6.51 \\
6.45 \\
6.39 \\
6.33 \\
6.27 \\
6 \cdot 21 \\
6.18 \\
6.15 \\
6.09 \\
6.03\end{array}$ & $\begin{array}{l}31 \\
32 \\
33 \\
34 \\
35 \\
36 \\
37 \\
38 \\
39 \\
40 \\
45 \\
50 \\
55 \\
60 \\
65 \\
70 \\
75 \\
80 \\
85 \\
90 \\
95 \\
100 \\
105 \\
110 \\
115 \\
120 \\
125 \\
130 \\
135 \\
140\end{array}$ & $\begin{array}{l}6 \cdot 00 \\
5 \cdot 97 \\
5 \cdot 94 \\
5 \cdot 88 \\
5 \cdot 85 \\
5 \cdot 82 \\
5 \cdot 76 \\
5 \cdot 73 \\
5 \cdot 70 \\
5 \cdot 67 \\
5 \cdot 52 \\
5 \cdot 37 \\
5 \cdot 22 \\
5 \cdot 13 \\
5 \cdot 04 \\
4 \cdot 95 \\
4 \cdot 86 \\
4 \cdot 77 \\
4 \cdot 68 \\
4 \cdot 62 \\
4 \cdot 53 \\
4 \cdot 47 \\
4 \cdot 41 \\
4 \cdot 35 \\
4 \cdot 29 \\
4 \cdot 23 \\
4 \cdot 17 \\
4 \cdot 14 \\
4 \cdot 08 \\
4 \cdot 04\end{array}$ \\
\hline
\end{tabular}

\begin{tabular}{|c|c|c|c|c|c|c|c|}
\hline$p \mathrm{H}$ & $\log a$ & $p \mathrm{H}$ & $\log a$ & $p \mathrm{H}$ & $\log a$ & $p H$ & $\log a$ \\
\hline 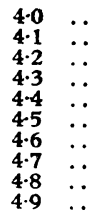 & $\begin{array}{l}35.92 \\
35.42 \\
34.92 \\
34.42 \\
33.92 \\
33.42 \\
32.92 \\
32.42 \\
31.95 \\
31 \cdot 45\end{array}$ & $\begin{array}{l}5.0 \\
5.1 \\
5.2 \\
5.3 \\
5.4 \\
5.5 \\
5.6 \\
5.7 \\
5.8 \\
5.9\end{array}$ & 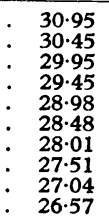 & $\begin{array}{l}6.0 \\
6.1 \\
6.2 \\
6.3 \\
6.4 \\
6.5 \\
6.6 \\
6.7 \\
6.8 \\
6.9\end{array}$ & $\begin{array}{ll}\because & 26.10 \\
\because & 25.66 \\
\because & 25.22 \\
\because & 24.78 \\
\because & 24.34 \\
\because & 23.93 \\
\because & 23.55 \\
\because & 23.17 \\
\because & 22.82 \\
\because & 22.47\end{array}$ & $\begin{array}{l}7.0 \\
7.1 \\
7.2 \\
7.3 \\
7.4 \\
7.5 \\
7.6 \\
7.7 \\
7.8 \\
7.9\end{array}$ & 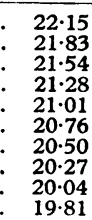 \\
\hline
\end{tabular}

OXALIC ACID
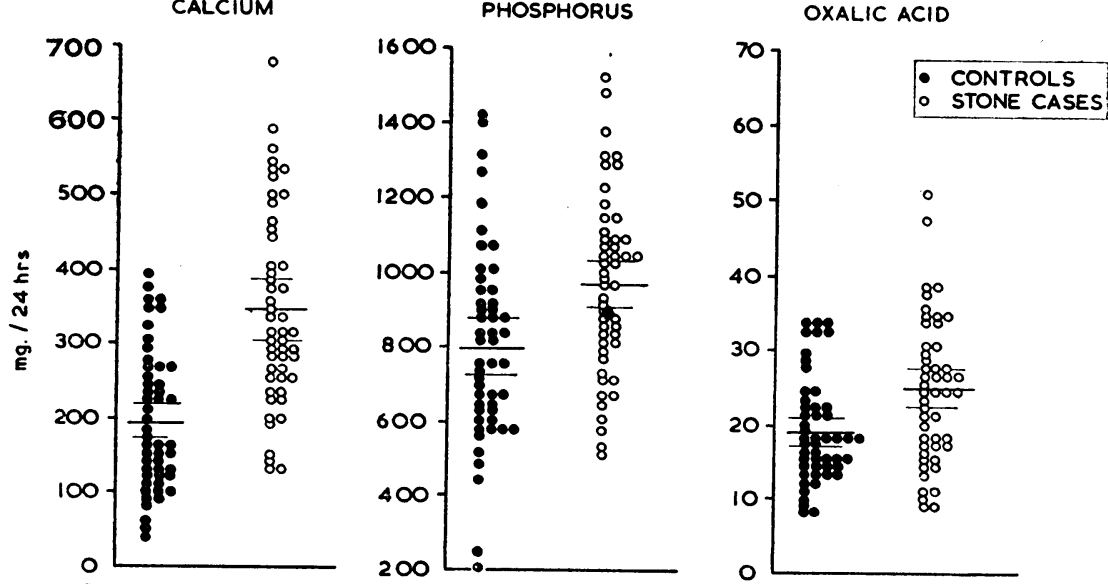

$50 \mathrm{male}$ cases of 1 - Total excretion (mg./24 hours) of calcium, phosphorus, and oxalic acid in $\mathrm{D}$ tal bars express formation product as $10^{-40}$ (calculated from the precipitation point data of Nordin (1959)). The solubility product of calcium oxalate is taken as $2.5 \times 10^{-8}$ (calculated from Hammarsten (1929) and the formation product as approximately $10^{-6}$ (our own unpublished observations). These values refer to solutions at $25^{\circ} \mathrm{C}$. and of ion strength 0.15 .

TABLE II.-Calculation of Urinary Calcium Oxalate Ion-products. Conversion Table for the Calculation of Calcium Oxalate Ion-products from the Urinary Concentrations of Ionic Calcium and Total Oxalate in $\mathrm{mg} . / 100 \mathrm{ml}$.

\begin{tabular}{|c|c|c|c|c|c|c|c|}
\hline $\begin{array}{c}{\left[\mathrm{Ca}^{++}\right]} \\
(\mathrm{mg} . / \\
100 \mathrm{ml} .)\end{array}$ & {$\left[\begin{array}{l}-\log \\
\mathrm{Ca}^{++}\end{array}\right]$} & $\begin{array}{c}{\left[\mathrm{Ca}^{++}\right]} \\
(\mathrm{mg} . / \\
100 \mathrm{ml} .)\end{array}$ & {$\left[\begin{array}{l}-\log \\
\mathrm{Ca}^{++}\end{array}\right]$} & $\begin{array}{c}{\left[\mathrm{H}_{2} \mathrm{C}_{2} \mathrm{O}_{4}\right]} \\
(\mathrm{mg} \cdot / \\
100 \mathrm{ml} .)\end{array}$ & $\begin{array}{l}-\log \\
\text { [Ox] }\end{array}$ & $\begin{array}{c}{\left[\mathrm{H}_{2} \mathrm{C}_{2} \mathrm{O}_{4}\right]} \\
(\mathrm{mg} \cdot] \\
100 \mathrm{ml} /)\end{array}$ & 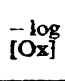 \\
\hline $\begin{array}{r}1 \\
2 \\
3 \\
4 \\
5 \\
6 \\
7 \\
8 \\
9 \\
10 \\
11 \\
12 \\
13 \\
14 \\
15\end{array}$ & $\begin{array}{l}3.60 \\
3.30 \\
3.13 \\
3.00 \\
2.90 \\
2.83 \\
2.76 \\
2.70 \\
2.65 \\
2.60 \\
2.56 \\
2.52 \\
2.49 \\
2.46 \\
2.43\end{array}$ & $\begin{array}{l}16 \\
17 \\
18 \\
19 \\
20 \\
21 \\
22 \\
23 \\
24 \\
25 \\
26 \\
27 \\
28 \\
29 \\
30\end{array}$ & $\begin{array}{l}2 \cdot 40 \\
2 \cdot 37 \\
2 \cdot 35 \\
2 \cdot 32 \\
2 \cdot 30 \\
2 \cdot 28 \\
2 \cdot 26 \\
2 \cdot 24 \\
2 \cdot 22 \\
2 \cdot 21 \\
2 \cdot 19 \\
2 \cdot 17 \\
2 \cdot 16 \\
2 \cdot 14 \\
2 \cdot 13\end{array}$ & $\begin{array}{l}1.0 \\
1.1 \\
1.2 \\
1.3 \\
1.4 \\
1.5 \\
1.6 \\
1.7 \\
1.8 \\
1.9 \\
2.0 \\
2.1 \\
2.2 \\
2.3 \\
2.4\end{array}$ & $\begin{array}{l}3.95 \\
3.91 \\
3.88 \\
3.84 \\
3.81 \\
3.78 \\
3.75 \\
3.72 \\
3.70 \\
3.68 \\
3.65 \\
3.63 \\
3.61 \\
3.59 \\
3.57\end{array}$ & $\begin{array}{l}2.5 \\
2.6 \\
2.7 \\
2.8 \\
2.9 \\
3.0 \\
3.1 \\
3.2 \\
3.3 \\
3.4 \\
3.5 \\
3.6 \\
3.7 \\
3.8 \\
3.9\end{array}$ & $\begin{array}{l}3.56 \\
3.54 \\
3.52 \\
3.51 \\
3.49 \\
3.48 \\
3.46 \\
3.45 \\
3.44 \\
3.42 \\
3.41 \\
3.40 \\
3.39 \\
3.37 \\
3.36\end{array}$ \\
\hline
\end{tabular}

\section{Results}

The total outputs of calcium, phosphorus, and oxalic acid in mg. per 24 hours are shown in Fig. 1. The mean excretion of each of these is significantly greater in the stone cases than in the controls.

The urinary hydrogen-ion concentrations do not differ significantly between the two groups, the $p H$ ranging in each from about 5.4 to 6.8 (Table III). The urine volumes of the stone cases tend to be larger than in the control series, but the difference is not significant (Table III).

TABLE III.-Urine pH, Volume, and Phosphorus and Oxalic Acid Con-

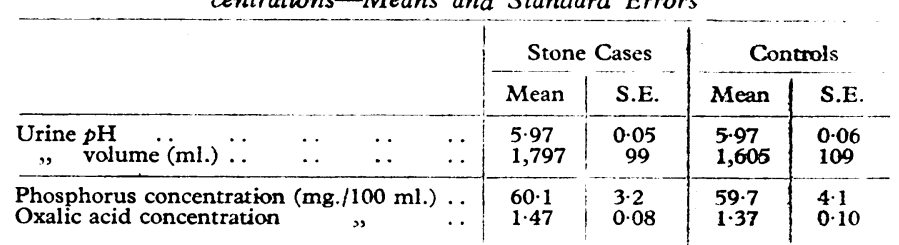

The concentrations of total and ionic calcium are shown in Fig. 2. The mean values are significantly higher in the stone cases than in the controls. The phosphate and oxalate concentrations, on the other hand, do not differ significantly between the two groups because the higher total outputs in the stone cases are offset by their slightly larger urine volumes (Table III).

The correlation between the ionic and total calcium concentrations is shown in Fig. 3, and is highly significant $(r=0.77, P<<0.001)$. The percentage of ionized calcium is very slightly higher in the stone group $(56.5 \pm 2.9)$ than in the controls $(55.4 \pm 2.9)$, but the difference is not significant.

The octocalcium phosphate and calcium oxalate ion-products in the two groups are shown in Figs. 4 and 5 and related to the formation and solubility products of the salts concerned. Twenty-eight of the control urines and 14 of the stone urines are undersaturated with respect to octocalcium phosphate (Fig. 4). This difference is highly significant (Table IV). Most of the stone urines and a large proportion of the controls fall within the so-called metastable region. 
Most of the calcium oxalate products lie within the metastable region but they tend to be higher in the stone cases (Fig. 5). If an arbitrary line is drawn at negative logarithm 6.5 ,
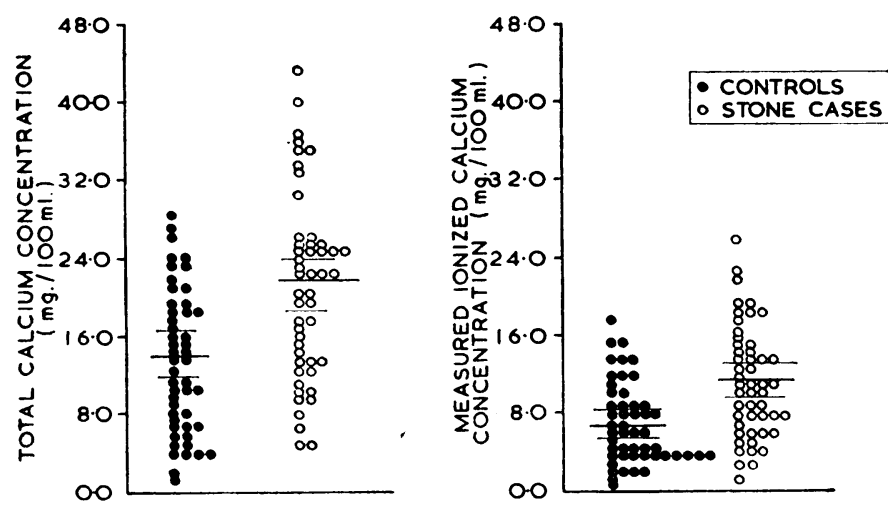

Fig. 2.-Total and ionized calcium concentrations in the stone cases and control subjects.

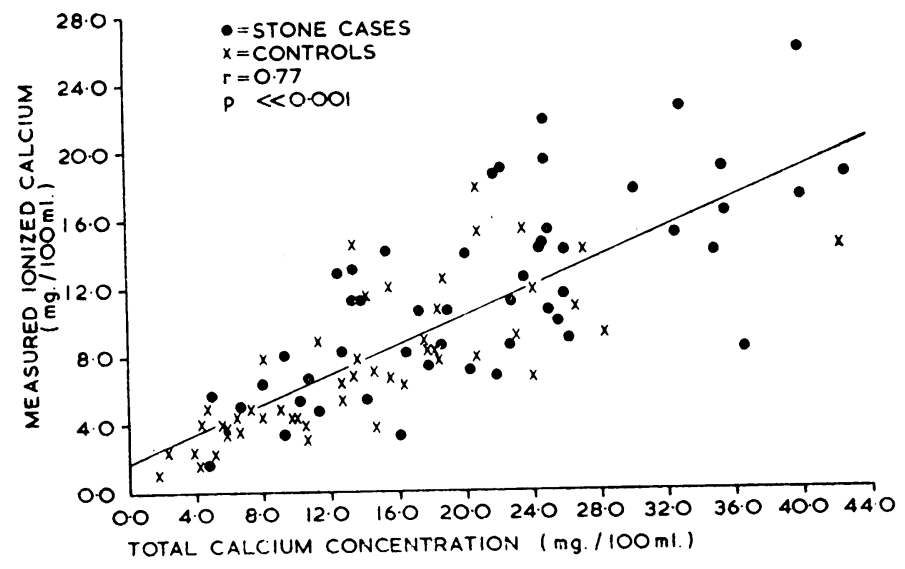

Fig. 3.- Relation between total and ionized calcium concentration in the urine of stone cases and control subjects.

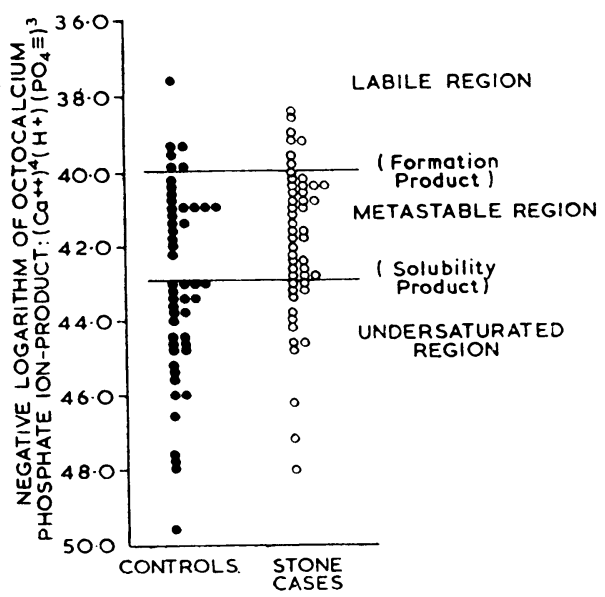

FIG. 4.-Octocalcium phosphate ion-products (expressed as negative logarithms) in control sub ects and stone cases, related to the solubility and formation products of the salt.

TABLB IV.-Octocalcium Phosphate and Calcium Oxalate Ion-productsSignificance of Difference Between Stone Cases and Controls by $x^{2}-$ Test

\begin{tabular}{|c|c|c|c|c|}
\hline & & $\begin{array}{c}\text { Ne. of } \\
\text { Stone Cases }\end{array}$ & $\begin{array}{c}\text { No. of } \\
\text { Controls }\end{array}$ & \\
\hline \multirow{2}{*}{$\begin{array}{l}\text { Octocalcium phosphate } \\
\text { ion-product } \\
{\left[\mathrm{Ca}^{++}\right]^{4}\left[\mathrm{H}^{+}\right]\left[\mathrm{PO}_{4}^{\prime}\right]^{3}}\end{array}$} & $>1.2 \times 10^{-43}$ & 36 & 22 & $x^{2}=6.94$ \\
\hline & $<1.2 \times 10^{-43}$ & 14 & 28 & $P<0.01$ \\
\hline \multirow{2}{*}{$\begin{array}{l}\text { Calcium oxalate ion- } \\
\text { product } \\
{\left[\mathrm{Ca}^{++}[\mathrm{Ox}]\right.}\end{array}$} & $>3.2 \times 10^{-7}$ & 33 & 15 & $x^{2}=11 \cdot 8$ \\
\hline & $<3.2 \times 10^{-7}$ & 17 & 35 & $P<0.001$ \\
\hline
\end{tabular}

then the difference in distribution between the two groups can be seen to be highly significant (Table IV).

When the matched pairs are examined individually it is found that in 30 pairs both the products are higher in the stone case than in the matched control and in eight the reverse is true. In 12 pairs one of the products is higher in the stone case and one in the control.

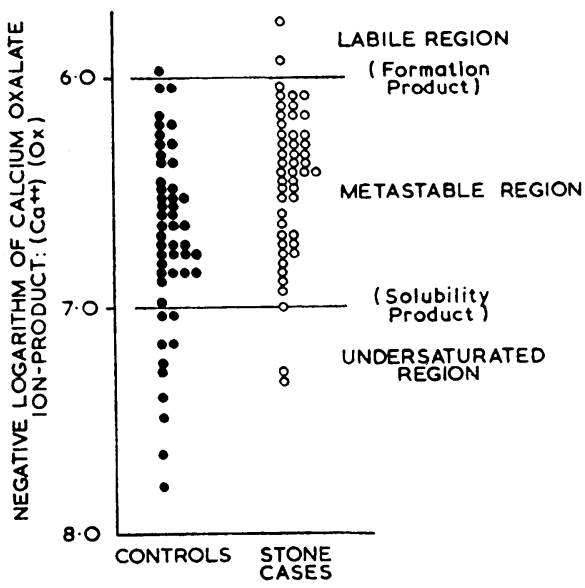

FIG. 5.-Calcium oxalate ion-products (expressed as negative logarithms) in control subjects and stone cases related to the formation and solubility products of the salt. (Note that no allowance has been made for the binding of oxalate ion to magnesium.)

\section{Discussion}

We have described a relatively simple method of determining the approximate calcium oxalate and octocalcium phosphate ion-products in urine. Such an ion-product may lie in one of three zones. Firstly, it may fall below the solubility product of the salt in a region where precipitation cannot occur and existing precipitates would be expected to dissolve. The urine is then undersaturated. Secondly, the product may lie above the solubility product of the salt concerned but below the level of spontaneous precipitation, which may be called the formation product. This is known as the metastable region, within which existing precipitates might be expected to grow but precipitation de novo does not occur unless the system is perturbed-for example, by the introduction of nucleating material. Thirdly, the product may be over the formation product in the region where spontaneous precipitation takes place.

The results in our first 50 male stone cases and age-matched male controls show that the octocalcium phosphate ionproducts tend to be distributed below and within the metastable region for this salt, only occasionally above it. By contrast, Elliot (1957) found that urine is generally undersaturated with respect to calcium phosphate, Raaflaub (1963) found it barely saturated, and Andrews et al. (1955) and Vermeulen et al. (1958) found it generally supersaturated. Virtually all the calcium oxalate ion-products, on the other hand, fall within the metastable region, confirming the conclusion reached by Andrews et al. (1955) and Miller et al. (1958) that urine is generally supersaturated with respect to calcium oxalate, but contrary to that reached by Raaflaub (1963) that normal urine is barely saturated with respect to the salt. Both products tend to be higher in the stone cases than in the controls, but the overlap is considerable.

Thus our results do not explain the initiation of stone disease but easily explain why stone formation, once begun, tends to persist or recur and why stones in situ are so notoriously difficult to dissolve. The immense difficulty in finding stone cases to study at the time when they are initiating their calculi hardly requires emphasis. 
When we come to analyse what is the main factor leading to the significant difference in the calcium oxalate and calcium phosphate ion-products between stone-formers and control subjects, our series would indicate that the ionic calcium concentration is of prime importance. Since this in turn is so dependent on the total calcium concentration (Fig. 3), and is a fairly constant proportion of it (about $56 \%$ of the total calcium concentration), it might be said that the difference in the total calcium concentration is what really governs the difference in the saturation level of most urines with respect to calcium oxalate and calcium phosphate. It is, of course, well documented that stone formation is often associated with hypercalciuria.

The proportion of urinary calcium existing in the ionized form in these urines is of the same order as that found by previous workers when using less satisfactory methods. It is slightly (though not significantly) higher in the stone cases than in the controls, as previously reported by Nordin and Tribedi (1962). Although this observation has not been confirmed by other workers (Hunt and King, 1963), it might be expected to be correct, since the higher total calcium concentration in stone cases in general (and in ours in particular) is not associated with any corresponding elevation of citrate, sulphate, or phosphate concentration. These are the three ions which, according to Raaflaub, are mainly responsible for the complexing of calcium in urine.

It must be pointed out that, although the stone-formers have higher absolute outputs of phosphate and oxalate (Fig. 1), when the concentrations of these anions are compared this difference is offset by the slightly higher urinary volumes of the stone group. Whether the latter is attributable to deliberate ingestion of extra fluid by the stone cases is difficult to say, but it does indicate how dependent the ion-products are upon water output and suggests a need to compare stoneformers and controls under conditions of identical fluid intake. This is in progress.

We believe that the calculation of urinary ion-products offers a new approach to the investigation of kidney stones and in particular should permit the assessment of medical treatment of stones in a more scientific manner than has hitherto been possible. The object of medical treatment must presumably be to produce an undersaturated urine. In our experience none of the medical treatments now available consistently achieves this objective.

\section{Summary}

A practicable method is described for the determination of calcium phosphate and calcium oxalate ion-products in urine.

Twenty-four-hour urines were collected from 50 male cases of renal-stone disease and 50 age-matched male controls and the concentrations of calcium, phosphate, and oxalate were determined.
The excretion of calcium, phosphorus, and oxalic acid was significantly higher in the stone cases than in the controls.

The concentrations of total calcium and ionic calcium were significantly higher in the stone cases than in the controls, but the concentrations of phosphate and oxalate did not differ significantly between the two groups.

Octocalcium phosphate ion-products were significantly higher in the stone cases than in the controls, but in both groups many of the values were within the metastable region.

Calcium oxalate ion-products were significantly higher in the stone cases than in the controls, but virtually all the values in both groups fell within the metastable region. These results do not explain the initiation of stone disease but do explain why kidney stones, once formed, tend to grow and are difficult to dissolve by medical means.

The factor of prime importance determining the difference in level of saturation of urine with respect to calcium phosphate and calcium oxalate was the total urinary calcium concentration.

It is suggested that the measurement of ion-products in urine might become the basis of assessing the medical treatment of kidney-stone disease.

We wish to acknowledge the assistance of Mr. P. M. Zarembski with the measurement of urinary oxalate, and to thank Mr. R. Dyer for performing many of the measurements of ionic calcium and Mr. R. Brennand for general technical assistance.

\section{REFERENCES}

Andrews, J. C., Yarbro, C. L., Golby, R. L., and Sell, I. T. (1955). ร. Ưrol., 73, 930.

Elliot, J. S. (1957). Ibid., 77, 269.

Ettori, J., and Scoggan, S. M. (1958). Arch. Biochem., 78, 213.

Hammarsten, G. (1929). C.R. Lab. Carlsberg, 17, No. 11, p. 1.

Hunt, L. D., and King, J. S., jun. (1963). Invest. Urol., 1, 83.

MacFadyen, I. J., Nordin, B. E. C., Smith, D. A., Wayne, D. J., and Rae, S. L. (1965). Brit. med. Ұ., 1, 161.

MacGregor, J., Nordin, B. E. C., and Robertson, W. G. (1965a). Nature (Lond.), 207, 861 .

___ Robertson, W. G., and Nordin, B. E. C. (1965b). Brit. F. Urol., 37, 518.

Miller, G. H., Vermeulen, C. W., and Moore, J. D. (1958). F. Urol., 79, 607.

Moreno, E. C., and Brown, W. E. (1960). Soil Sci. Soc. Amer. Proc., 24, 99.

Nordin, B. E. C. (1959), Brit. 7. Urol., 31, 404.

- and Tribedi, K. (1962). Lancet, 1, 409.

Raaflaub, J. (1962). Hoppe-Seylers, Z. physiol. Chem., 328, 198.

- (1963). Helv. med. Acta, 30, 724

Thomas, W. C., and Howard, J. E. (1959). Trans. Ass. Amer. Phycns, 72,181 .

Vermeulen, C. W., Lyon, E. S., and Miller, G. H. (1958). F. Urol. 79, 596.

— Miller, G. H., and Chapman, W. H. (1956). Ibid., 75, 592.

Zarembski, P. M., and Hodgkinson, A. (1965a). Biochem. 7., 96, 218. (1965b). Ibid., 96, 717. 